\title{
UNA PROPUESTA METODOLÓGICA PARA ESTABLECER NIVELES DE MATERIALIDAD EN RESPUESTA A LOS RIESCOS DE ERRORES IMPORTANTES EN LOS ESTADOS FINANCIEROS
}

A methodological proposal for establishing materiality levels in response to the risks of material errors in the financial statements

Tec Empresarial, Enero - Abril, 2019

Vol 13 Núm 1 / p. 35 - 52

Eduardo Sosa Mora

esossa@itcr.ac.cr

eduardo.sosamora@ucr.acr.cr

Máster en Evaluación de Programas y Proyectos de Desarrollo por la Universidad de Costa Rica. Auditor y consultor independiente. Profesor del Instituto Tecnológico de Costa Rica y de la Universidad de Costa Rica.

- Recepción del artículo: 8 de diciembre, 2016. - Aprobación del artículo: 18 de enero, 2018.

\section{ABSTRACT}

In order to issue an opinion on the compliance of the financial statements of an entity with International Financial Reporting Standards (IFRS), the auditor must obtain reasonable assurance that such statements are free of material inaccuracies. However, the risk of reaching that conclusion when the financial statements are really distorted by material misstatement is always present. Therefore, the auditor must manage audit risk to carry it a reasonably low level, by reducing the risk of detection. A mechanism that helps to achieve this goal is to establish levels of materiality for the financial statements for some sections and elements of these statements. This article summarizes the main conceptual foundations of audit risk and presents a methodological proposal to establish levels of materiality in response to the risks of material misstatements in the financial statements with the support of an illustrative case.
Keywords: audit, financial statements, materiality, audit risk, inherent risk, control risk, risk of material inaccuracy, detection risk, tolerable error.

\section{RESUMEN}

Para poder emitir una opinión respecto a la conformidad de los estados financieros de una entidad con las Normas Internacionales de Información Financiera (NIIF), el auditor debe obtener razonable seguridad de que dichos estados están libres de incorrecciones de importancia relativa. No obstante, siempre está presente el riesgo de auditoría que consiste en que el auditor llegue a esa conclusión cuando realmente los estados financieros están distorsionados por incorrecciones materiales. Ello impone al auditor el deber de gestionar el riesgo de auditoría para llevarlo a un nivel razonablemente bajo mediante la reducción del riesgo de detección. Un mecanismo que ayuda a lograr este propósito es el establecimiento de niveles de materialidad para los estados financieros como un todo, para determinadas secciones y para las partidas de estos. En este artículo se exponen de manera resumida los principales fundamentos conceptuales del riesgo de auditoría y se presenta una propuesta metodológica para establecer niveles de materialidad, en respuesta a los riesgos de incorrecciones materiales en los estados financieros, con el apoyo de un caso ilustrativo.

Palabras Clave: auditoría, estados financieros, materialidad, riesgo de auditoría, riesgo inherente, riesgo de control, riesgo de incorrección material, riesgo de detección, error tolerable. 


\section{》INTRODUCCIÓN}

La auditoría cumple una importante función en el mundo actual porque, al expresar opinión sobre la razonabilidad de los estados financieros de las empresas, los auditores contribuyen a aumentar la confianza de accionistas, inversionistas, prestamistas y otros agentes económicos en esos estados, de manera que estos les puedan ser útiles para tomar decisiones.

Para poder expresar una opinión sobre la conformidad de los estados financieros con el marco de información financiera aplicable, el auditor debe obtener razonable seguridad de que dichos estados están libres de errores de importancia relativa. Debido a la naturaleza de la auditoría, siempre existe el riesgo de concluir que los estados financieros están libres de esas incorrecciones y expresar una opinión limpia, cuando en realidad esos estados sí están distorsionados por representaciones erróneas significativas. Esto es lo que se conoce como riesgo de auditoría.

Si bien, es imposible eliminar el riesgo de auditoría, los auditores deben reducirlo a un nivel adecuadamente bajo. Para ello, identifican y valoran los riesgos de que existan incorrecciones materiales en los estados financieros y diseñan respuestas a esos riesgos para minimizar la probabilidad de que tales errores -de existir- no sean detectados por los procedimientos de auditoría. Un mecanismo muy útil para lograr esto último es establecer umbrales de materialidad para los estados financieros, para secciones y para partidas de estos, que al indicar montos máximos de error aceptable contribuyen a evitar que el importe total de las incorrecciones materiales detectadas y no detectadas afecte la razonabilidad de esos estados.

\section{METODOLOGÍA}

La investigación objeto de este artículo es de tipo cualitativo. Consiste en una revisión de la literatura y en la presentación de una propuesta metodológica con el apoyo de un caso ilustrativo.

En este artículo se exponen -de manera resumida- los principales fundamentos conceptuales del riesgo de auditoría

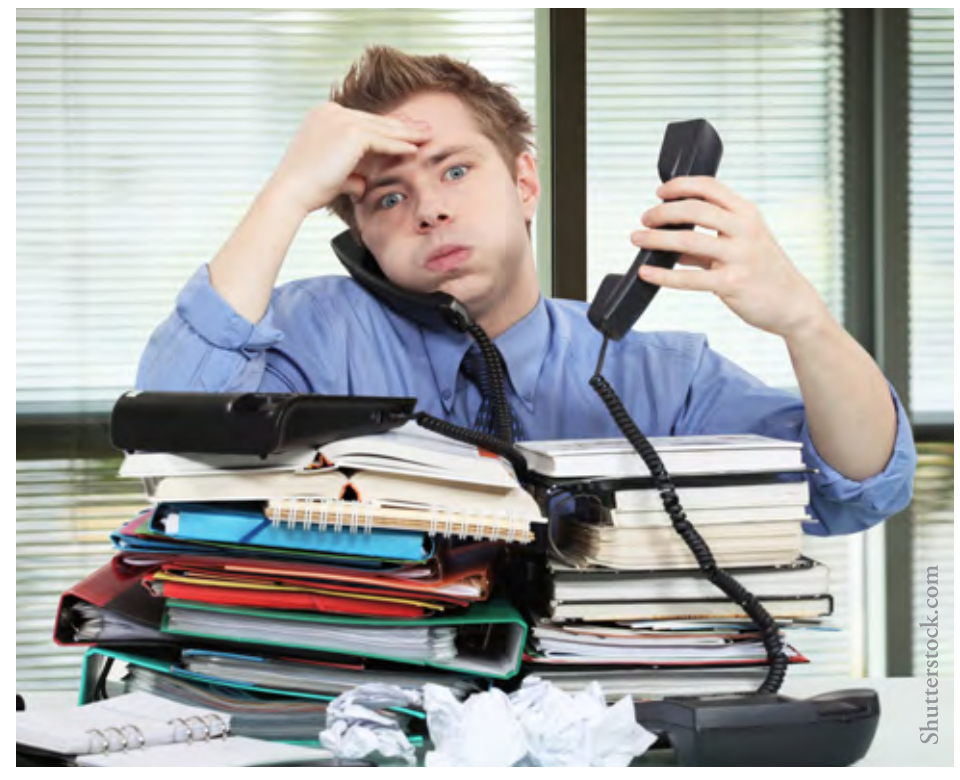

a partir de una revisión de la literatura que proporciona su marco de referencia conceptual (Gutiérrez y Maz, s.f.). Partiendo de ese marco conceptual, se formula una propuesta metodológica para establecer la materialidad en términos monetarios en los estados financieros, a partir de los niveles evaluados del riesgo de incorrección material y con el apoyo de un caso desarrollado a partir de una situación real.

Los nombres de la firma de auditores independientes y de la empresa del caso, así como la descripción de su giro de negocio y las cifras contables, han sido modificados para guardar la confidencialidad.

\section{REVISIÓN DE LITERATURA}

\section{La confianza en los estados financieros y el auditor independiente}

En la compleja sociedad moderna, caracterizada por la globalización económica y por el vertiginoso desarrollo de las tecnologías de la información, los agentes económicos deben confiar cada vez más en los estados financieros que emiten las compañías para apoyar la toma de decisiones.

El fenómeno de la globalización ha adquirido tales dimensiones que ha sido inevitable la emisión y la adopción, en mayoría de países, de un conjunto uniforme de estándares 
internacionales (las Normas Internacionales de Información Financiera -NIIF-) para regular y uniformar los procesos de reconocimiento, medición, presentación y revelación de la información financiera de las compañías, y con esto facilitar que los diferentes usuarios dispongan de información financiera sobre distintas compañías, independientemente de donde estén localizadas. La normativa contable es ahora una normativa global que se ajusta a las necesidades del entorno económico internacional.

De conformidad con la Norma Internacional de Contabilidad No. 1 -NIC 1- (IASB, 2011), los estados financieros son una representación estructurada de la situación financiera y del rendimiento financiero de una entidad que tienen como propósito proporcionar información acerca de la situación financiera, del rendimiento financiero y de los flujos de efectivo a una amplia variedad de usuarios, quienes usualmente no están en condiciones de exigir informes a la medida de sus necesidades específicas. De aquí la relevancia de estos informes financieros en la dinámica economía moderna.

Para fundamentar la toma de decisiones en la información que proporcionan los estados financieros, los usuarios necesitan tener seguridad de que estos representan razonablemente la situación financiera, el rendimiento financiero, los cambios en el patrimonio y los flujos de efectivo de una entidad, acorde con las NIIF. Es aquí donde la función de auditoría de los estados financieros adquiere relevancia porque esta actividad es la que, precisamente según la Norma Internacional de Auditoría 200 -NIA 200- (IFAC, 2011), permite aumentar el grado de confianza de los usuarios en los estados financieros, mediante la expresión de una opinión del auditor respecto a si dichos estados han sido preparados, en todos los aspectos sustanciales, en conformidad con ese marco de información financiera.
Acorde con la misma norma, para estar en condiciones de expresar tal opinión, el auditor debe obtener evidencia suficiente y adecuada que le proporcione razonable seguridad de que los estados financieros están libres de incorrecciones materiales, debidas ya sea al fraude o al error.

Para lograr ese objetivo, el auditor identifica y valora los riesgos de que existan incorrecciones materiales en los estados financieros, mediante el conocimiento de la entidad, su entorno y su control interno. Asimismo, obtiene evidencia adecuada y suficiente por medio del diseño y la ejecución de procedimientos apropiados en respuesta a los riesgos evaluados (IFAC, 2011). Esto incluye la planificación y ejecución de procedimientos sustantivos para comprobar si las representaciones de los estados financieros se ajustan a los requerimientos establecidos en las NIIF.

\section{El riesgo de auditoría}

El auditor debe obtener un nivel razonable de seguridad de que los estados financieros examinados están libres de incorrecciones materiales, no una seguridad absoluta porque eso es imposible, debido a que existen limitaciones inherentes a la auditoría, como la naturaleza de la información financiera y de los procedimientos que realiza el auditor, lo mismo que restricciones en cuanto a tiempo y costo, en virtud de las cuales la evidencia de auditoría es más de naturaleza persuasiva que concluyente (NIA 500, IFAC, 2011).

Existe el riesgo de que el auditor concluya que los estados financieros examinados están exentos de representaciones erróneas significativas, cuando en realidad sí están distorsionados por incorrecciones materiales, es decir, existe el riesgo de que el auditor exprese una opinión limpia sobre tales estados financieros, cuando debió haber expresado una opinión desfavorable (negativa), o una con salvedades. Esto es lo que la NIA 200 (IFAC, 2011) define como riesgo de auditoría. 》》 
8El riesgo de auditoría, a su vez, está en función del riesgo de incorrección material y del riesgo de detección. El primero es responsabilidad de la entidad, pero el auditor debe valorarlo, mientras que el segundo sí está bajo el control y la responsabilidad del auditor.

El riesgo de incorrección material, de acuerdo con la NIA 200 (IFAC, 2011), es el riesgo de que los estados financieros contengan errores significativos antes de la ejecución de la auditoría y es el resultado de dos componentes, que son el riesgo inherente y el riesgo de control. El primero es la susceptibilidad de una partida, aseveración o grupo de transacciones a la presencia de errores materiales antes de considerar los respectivos controles, mientras que el segundo consiste en la posibilidad de que el sistema de control interno no permita prevenir, detectar y corregir oportunamente cualesquiera incorrecciones materiales en una aseveración, tipo de transacción, saldo o revelación de información.

El riesgo inherente está determinado por aspectos tales como el volumen transaccional, la naturaleza de la partida, la complejidad de los cálculos y registros contables para obtener su saldo y la presencia de elementos de índole subjetiva, como el juicio y las hipótesis de la dirección para realizar estimaciones contables como las pérdidas por incobrabilidad de la cartera, deterioro de los inventarios y deterioro del valor de los activos en general.

Por su parte, el riesgo de control está en función de la eficacia del sistema de control establecido para prevenir, detectar y corregir oportunamente incorrecciones que por sí solas, o en combinación con otras, podrían llegar a ser materiales.

El riesgo inherente y el riesgo de control, determinantes del riesgo de incorrección material, están estrechamente relacionados porque si un alto nivel de riesgo inherente en una partida es mitigado con un adecuado sistema de control interno, como resultado se obtendrá un bajo o moderado riesgo de incorrección material. En el otro extremo, la posible presencia de incorrecciones materiales debido a un alto nivel de riesgo inherente en una partida se potencia aún más ante la presencia de un alto riesgo de control, debido precisamente a la inexistencia de adecuados procedimientos que neutralicen el riesgo inherente.

En esta línea de pensamiento, Mercado (2010) visualiza gráficamente la relación entre el riesgo inherente y el riesgo de control como una matriz:

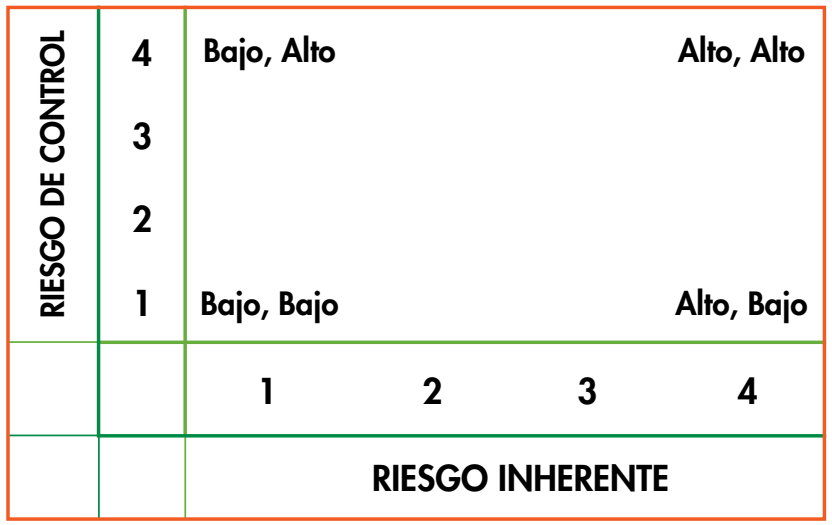

En el extremo inferior izquierdo se tiene una combinación de un bajo grado de riesgo inherente y un bajo riesgo de control, lo que redunda en un nivel bajo de riesgo de incorrección material. Al ejecutar la auditoría, las partidas que presenten esta combinación de riesgos podrían ser auditadas aplicando pruebas de controles y pruebas analíticas sustantivas.

En el extremo superior izquierdo se presenta la combinación de bajo riesgo inherente y alto riesgo de control. Como el riesgo de control es alto para estas partidas, eso significa que existen deficiencias significativas, ya sea en el diseño o en la operación del sistema de control interno, o bien, que los controles son inexistentes. Debido a esto, los auditores, al examinar estas partidas, no confían en el control interno y realizan procedimientos sustantivos de nivel básico debido al bajo nivel de riesgo inherente.

En la esquina inferior derecha se ubica la combinación alto riesgo inherente-bajo riesgo de control. Debido a la efectividad de los controles establecidos para mitigar el alto riesgo inherente, el auditor puede aplicar un enfoque combinado de pruebas de cumplimiento con pruebas sustantivas al examinar los saldos de las partidas que estén dentro de esta combinación de riesgos.

Por último, el nivel más crítico desde el punto de vista de auditoría se ubica en la esquina superior derecha, donde se combinan altos niveles de riesgo inherente y de control, que se traducen en niveles críticos de riesgo de incorrección material. Para las partidas que presenten esta condición, se requiere adoptar un enfoque de auditoría orientado a la ejecución de pruebas sustantivas de detalle con alcance amplio. 
Quintanar (1985), Arens, Eider y Breasley (2007 y Whittington y Pany (2006) coinciden en que la relación entre el riesgo inherente y el riesgo de control es multiplicativa. Esto significa que, entre más alto sea el riesgo de control, se propician las condiciones para potenciar más la probabilidad de que existan incorrecciones materiales en los saldos de las partidas con alto riesgo inherente. De hecho, según esos autores, la relación entre los tres componentes del riesgo de auditoría es de naturaleza multiplicativa y puede ser representada como:

\section{$\mathrm{RA}=\mathrm{RI} X \mathrm{RC} X \mathrm{RD}$}

En donde:

- RA: Riesgo de auditoría

- RI: Riesgo inherente

- RC: Riesgo de control

- RD: Riesgo de detección

El riesgo de detección es la probabilidad de que los procedimientos de auditoría aplicados no detecten incorrecciones que sean materiales, tanto de manera individual como de manera agregada con otras incorrecciones. Este riesgo depende de la eficacia de los procedimientos de auditoría diseñados, así como de su correcta aplicación por el auditor y está influido por factores como la adecuada planificación de la auditoría, la apropiada designación del equipo de auditoría, la correcta y oportuna supervisión de éste y la aplicación del escepticismo profesional (NIA 200, IFAC, 2011).

El riesgo de detección, a su vez, está compuesto por el riesgo de muestreo y el riesgo ajeno al muestreo, según la NIA 530 (IFAC, 2011). El primero es el riesgo de que una conclusión del auditor a partir de una muestra pueda diferir de la que habría obtenido aplicando el mismo procedimiento de auditoria a toda una población, mientras que el segundo tiene su origen en razones ajenas al muestreo, como, por ejemplo, la aplicación incorrecta de procedimientos de auditoría, la ejecución de procedimientos inadecuados, la interpretación incorrecta de la evidencia, la falta de reconocimiento de una incorrección material, la supervisión insuficiente del personal, entre otros factores.
La composición del riesgo de auditoría se ilustra de manera resumida en la figura 1 .

El auditor podrá alcanzar un nivel razonable de seguridad de que los estados financieros están exentos de incorrecciones materiales cuando logre reducir a un nivel aceptablemente bajo el riesgo de auditoría, por medio de la obtención de la evidencia suficiente y adecuada. Para ello, requiere identificar y valorar la presencia de factores de riesgo inherente y de riesgo de control, tanto en los estados financieros en su conjunto, como en partidas y aseveraciones específicas; además, debe planificar y ejecutar procedimientos de auditoría para reducir el riesgo de detección.

Esto significa que el auditor administra el riesgo de auditoría mediante la reducción del riesgo de detección, de manera que el nivel aceptable de riesgo de detección es inversamente proporcional a los riesgos evaluados de incorrección material en los saldos de las diferentes partidas de los estados financieros.

En la práctica, para aquellas partidas respecto de las que se haya calificado más alto el riesgo de incorrección material, el auditor debe planear y aplicar procedimientos específicos de auditoría más efectivos, detallados y exhaustivos para obtener evidencia de auditoría más convincente, precisamente para contrarrestar los posibles efectos del riesgo de incorrección material sobre su opinión sobre estados financieros. No obstante, en vista de las limitaciones propias de la naturaleza de la $\gg$

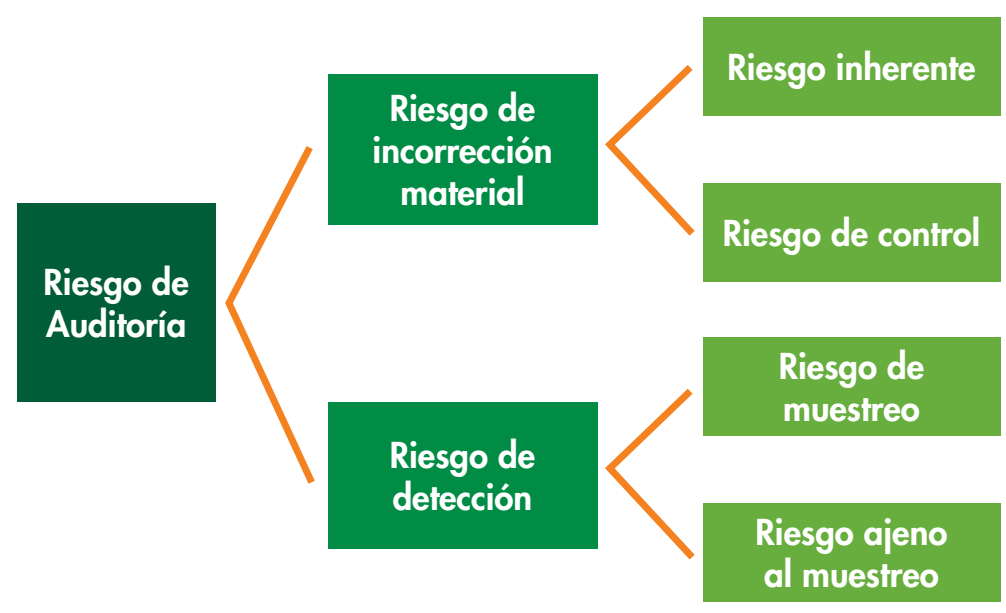

Figura 1: Composición del riesgo de auditoría 


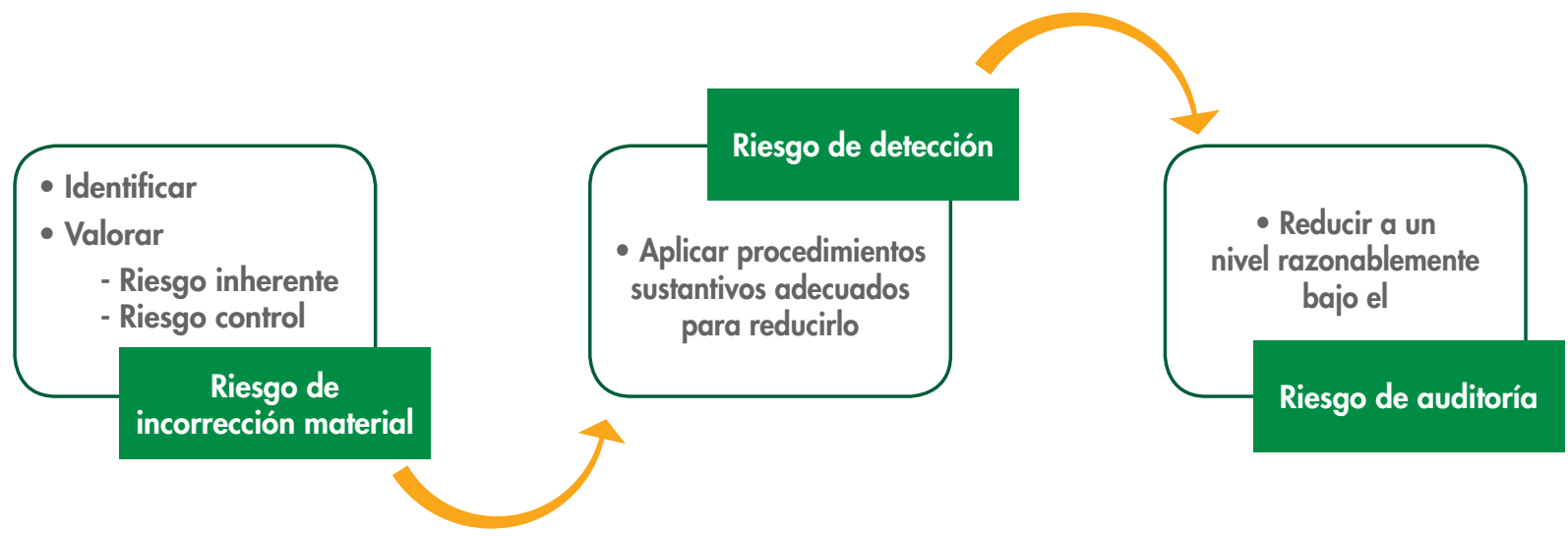

Figura 2: Estrategia general para reducir el riesgo de auditoría

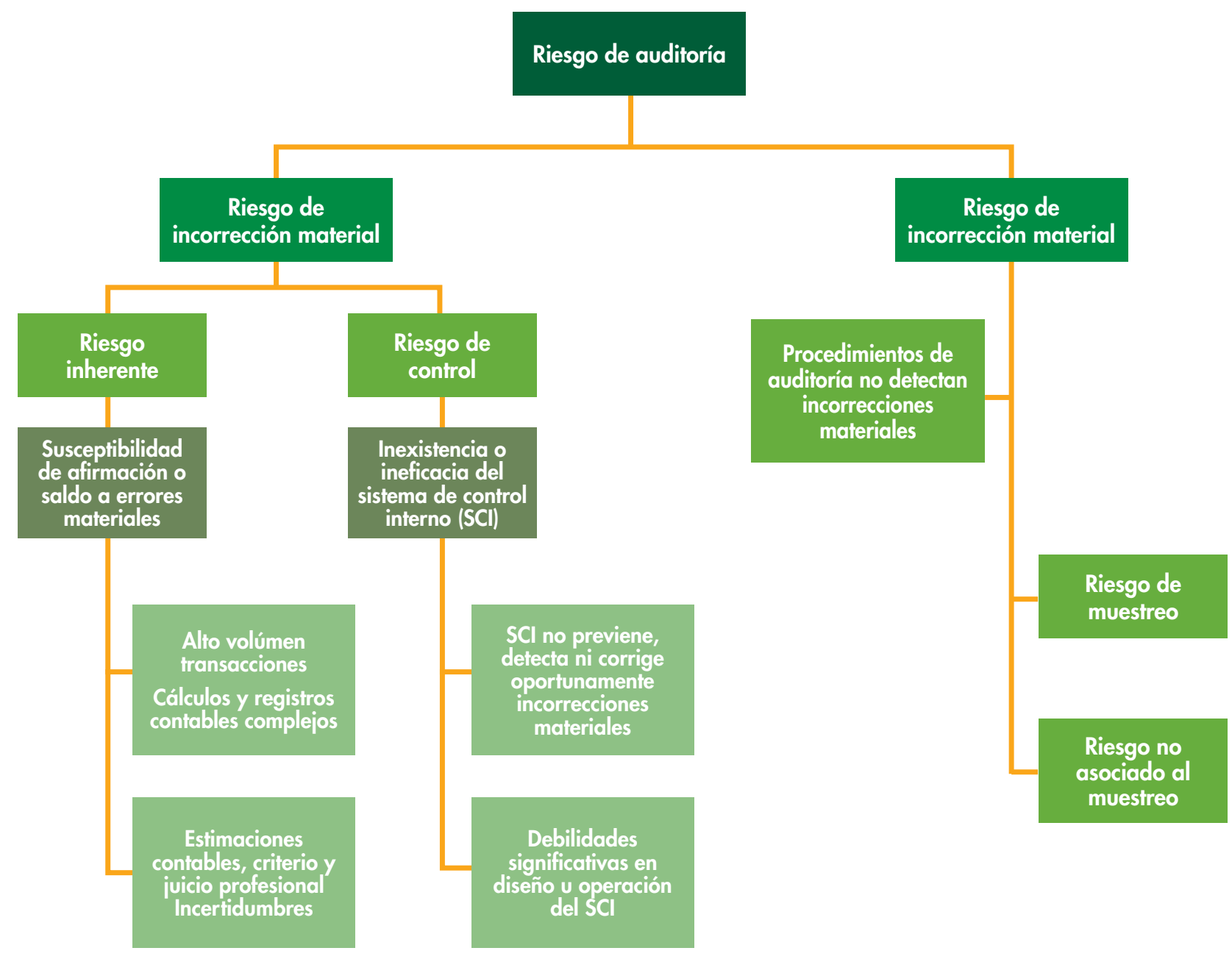

Figura 3: Resumen de los elementos componentes del riesgo de auditoría 


\section{Si bien, es imposible eliminar el riesgo de auditoría, los auditores deloen reducirllo a un nivel adecuadamente bajo}

d) auditoría, el riesgo de detección puede reducirse sustancialmente, pero no es posible eliminarlo del todo.

En la figura 2 se ilustra la estrategia general para reducir el riesgo de auditoría y en la figura 3 se presenta un resumen de los elementos componentes del riesgo de auditoría.

\section{Riesgo de auditoría, materialidad y error tolerable}

Un procedimiento que se utiliza en auditoria para responder a los riesgos de incorrecciones materiales consiste en establecer los niveles de materialidad para los estados financieros en conjunto, lo mismo que para cada una de las partidas de estos.

Acorde con la NIA 320 (IFAC, 2011), las incorrecciones se califican como materiales si razonablemente se puede prever que estas -ya sea en forma individual o agregada con otras incorrecciones- influyan en las decisiones económicas que los usuarios toman basándose en los estados financieros. Señala esta norma que los juicios sobre la importancia relativa se realizan teniendo en consideración las circunstancias en que ocurren y están condicionados por la naturaleza y por la magnitud de una incorrección, o bien por la combinación de ambos factores.

Desde una perspectiva más práctica, para Mendoza (2009), la materialidad consiste en establecer una medida de tolerancia a errores o desviaciones que puedan existir y no sean detectados por la auditoría, con el fin de minimizar el riesgo de expresar una opinión sin salvedad sobre estos estados financieros que contienen errores importantes.

El auditor realiza valoraciones acerca de las magnitudes de las incorrecciones que deberían considerarse como materiales, durante las etapas de planificación y de ejecución de la auditoría (NIA 320, IFAC, 2011). En ambas fases, el auditor formula juicios acerca de la materialidad que le sirven para establecer la naturaleza, la oportunidad y el alcance de los procedimientos para la valoración del riesgo, para identificar riesgos de incorrección material y para determinar la naturaleza, la oportunidad y la extensión de los procedimientos de auditoría que deberá ejecutar posteriormente. Durante la ejecución de la auditoría, esos juicios también le sirven al auditor para evaluar el efecto de las representaciones erróneas no corregidas al formarse su opinión sobre los estados financieros.

Siguiendo lo que señala la NIA 320 (IFAC, 2011), la determinación de la importancia relativa es un asunto que requiere de la aplicación del juicio profesional por parte el auditor en la valoración de diversos factores cuantitativos y cualitativos. Para efectos prácticos, normalmente el ejercicio de ese juicio profesional finalmente se resume en la aplicación de un porcentaje a una referencia seleccionada para establecer la materialidad para los estados financieros en su conjunto. Así, por ejemplo, el auditor puede seleccionar el total de activos, el total patrimonio, o bien, las ventas netas como referentes y aplicarles un determinado porcentaje para establecer la materialidad global para los estados financieros como un todo. En el cuadro 1 se presentan varios ejemplos de determinación de la materialidad para los estados financieros en conjunto.

La selección de la referencia y del porcentaje por aplicar es un asunto de criterio profesional, basado en la experiencia en la ejecución de otras auditorías de compañías similares y en la apreciación sobre las valoraciones sobre la importancia relativa que podrían formular diferentes usuarios de la información financiera, entre otros criterios. No existen recetas para esto. $\gg$

Cuadiro 1: Ejemplos ilustrativos del cálculo de la materialidad al nivel de estados financieros

\begin{tabular}{|c|c|c|c|}
\hline Referente & $\begin{array}{c}\text { Saldo según } \\
\text { estados } \\
\text { financieros } \\
\text { (millones } \\
\text { de colones) }\end{array}$ & Porcentaje & $\begin{array}{c}\text { Monto } \\
\text { Materialidad } \\
\text { nivel de } \\
\text { estados } \\
\text { financieros }\end{array}$ \\
\hline Activo Total & 1500 & $3 \%$ & 45,0 \\
\hline Patrimonio & 400 & $12 \%$ & 48,0 \\
\hline Ventas netas & 800 & $0.5 \%$ & 40,0 \\
\hline
\end{tabular}


\) Según a NIA 320 (IFAC, 2011), la materialidad para la fase de ejecución de la auditoría consiste en el importe o en los importes que el auditor establece, por debajo de la importancia relativa establecida para los estados financieros en su conjunto, con el fin de reducir hasta un nivel adecuadamente bajo la probabilidad de que la suma de las representaciones erróneas no corregidas y las no detectadas por el auditor supere precisamente el monto de la materialidad definida para los estados financieros en conjunto.

Siguiendo las ilustraciones del cuadro 1 , el nivel de materialidad para la ejecución de la auditoría deberá ser ubicado en una cifra inferior a 45, 48 o 40 millones de colones, dependiendo de cuál sea el referente utilizado, de tal manera que la suma de las representaciones erróneas no corregidas no deberá exceder de esas cifras.

Si la suma de las incorrecciones acumuladas identificadas durante la ejecución de la auditoría se aproxima a la importancia relativa determinada siguiendo el procedimiento descrito, puede existir un nivel de riesgo superior al nivel aceptablemente bajo de que las posibles incorrecciones no detectadas más las incorrecciones acumuladas durante la auditoría, en conjunto, superen el importe de la materialidad de los estados financieros. Esto obedece a que podrían existir incorrecciones no detectadas derivadas del riesgo de detección.

De la misma manera, durante la ejecución de la auditoría se establecen niveles de importancia relativa para determinados

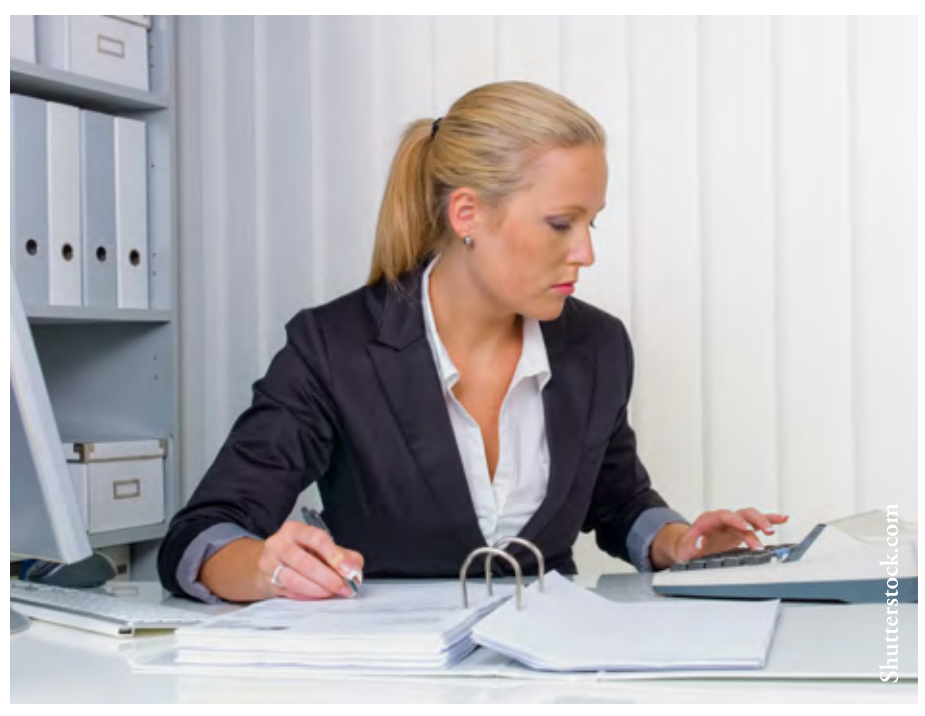

saldos, cuentas o tipos de transacciones, también con el fin de reducir a un nivel razonablemente bajo la probabilidad de que la suma de las representaciones erróneas no corregidas y las no detectadas en esos saldos, cuentas o tipos determinados de transacciones, supere el respectivo nivel de importancia relativa.

Algunos auditores establecen niveles de materialidad para cada estado financiero y para sus diferentes secciones. Por ejemplo, se podría establecer la materialidad del estado de situación financiera en un $4 \%$ de los activos totales y la del estado de resultado integral en un $10 \%$ de la utilidad antes de impuestos. Asimismo, pueden definirse niveles de materialidad para el activo corriente, para el pasivo corriente y para el pasivo total.

Finalmente, el auditor establece importes de materialidad para cada partida de los estados financieros, con el fin de asegurar que la suma de las representaciones erróneas identificadas durante la auditoría más las incorrecciones no detectadas no superen, precisamente, ese nivel de materialidad. Esto se conoce también con el nombre de error o incorrección tolerable que, según la NIA 530 (IFAC, 2011), es el importe que establece el auditor con la finalidad mencionada.

\section{PROPUESTA METODOLÓGICA Y CASO ILUSTRATIVO}

En este apartado se presenta la propuesta metodológica para el establecimiento de los niveles de materialidad en los estados financieros, en función de los niveles evaluados de riesgo inherente y de riesgo de control. Esto se hace con la ayuda de un caso que describe el procedimiento utilizado por una firma de contadores públicos para tal efecto, mediante el cual establece los niveles de error tolerable de las diferentes cuentas, como guía para orientar el trabajo de reducir al mínimo el riesgo de detección y, con ello, disminuir el riesgo de auditoría.

\section{Presentación}

Un procedimiento que se utiliza en auditoria para responder a los riesgos de incorrecciones materiales consiste en establecer los niveles de materialidad para los estados financieros en conjunto, lo mismo que para cada una de las partidas de estos. 
La firma de contadores públicos autorizados, P y G Asociados, fue contratada para realizar la auditoría de los estados financieros de la Compañía Productora de Alimentos para Mascotas S.A. al 30 de setiembre del 2015. Esta compañía se dedica a la producción y distribución de alimentos concentrados para perros, gatos y aves. Sus principales clientes son las grandes cadenas de supermercados del país.

Los auditores han concluido las etapas de conocimiento de la entidad y del negocio, incluyendo la evaluación del control interno, lo mismo que la identificación y valoración preliminar de los riesgos de incorrección material.

Antes de ejecutar procedimientos sustantivos, los auditores proceden a calcular la materialidad de cada uno de los estados financieros, así como el porcentaje y monto de error tolerable para las distintas cuentas, de acuerdo con la metodología que se describe a continuación.

\section{Materialidad para el estado de situación financiera en su conjunto y sus secciones}

Para establecer el nivel de materialidad de dicho estado financiero en su conjunto, así como para las diferentes secciones de estos, su firma ha establecido los siguientes criterios y porcentajes:

\begin{tabular}{|c|c|}
\hline Referente & Porcentaje \\
\hline Total de activo corriente & $4,50 \%$ \\
\hline Total de pasivo corriente & $4,50 \%$ \\
\hline Total de pasivos & $5,00 \%$ \\
\hline
\end{tabular}

El 6,5\% del activo total es el umbral de la materialidad del estado de situación financiera en su conjunto. La suma de los errores tolerables para las cuentas de este estado no debe exceder de este umbral. También se espera que el total de errores tolerables de cada una de las secciones no supere el umbral de materialidad de la respectiva sección.

\section{Materialidad para el estado de resultados integral como un todo}

El nivel de materialidad para este estado financiero en su conjunto se ha establecido en un $6 \%$ de la utilidad neta del período después del pago del impuesto sobre la renta.

\section{Error tolerable para las partidas de los estados financieros}

Para establecer el error tolerable de cada una de las partidas de los estados financieros se utiliza un criterio cuantitativo y otro cualitativo, los cuales se integran posteriormente, de acuerdo con el procedimiento que se explica a continuación:

\section{- Criterio cuantitativo}

Este criterio consiste en determinar porcentajes de error tolerable para las partidas de los estados financieros de acuerdo con su peso relativo con respecto al total de activos, de tal manera que a los rubros cuyos saldos sean mayores se les apliquen porcentajes menores de error tolerable, de acuerdo con los siguientes rangos:

\begin{tabular}{|c|c|}
\hline $\begin{array}{c}\text { Rango de valores relativos } \\
\text { respecto al activo total }\end{array}$ & $\begin{array}{c}\text { Porcentaje } \\
\text { para establecer } \\
\text { el monto de } \\
\text { error tolerable } \\
\text { por partida }\end{array}$ \\
\hline Hasta $20 \%$ del activo total & $1,50 \%$ \\
\hline Más de $20 \%$ hasta $40 \%$ del activo total & $1,25 \%$ \\
\hline Más de $40 \%$ del activo total & $0,75 \%$ \\
\hline
\end{tabular}

Para el estado de resultados integral, el error tolerable de cada partida se determina en función de su peso relativo respecto de las ventas netas, según la siguiente escala:

\begin{tabular}{|c|c|}
\hline $\begin{array}{c}\text { Rango de valores relativos } \\
\text { respecto a las ventas netas }\end{array}$ & $\begin{array}{c}\text { Porcentaje } \\
\text { para establecer } \\
\text { el monto de } \\
\text { error tolerable } \\
\text { por partida }\end{array}$ \\
\hline Hasta $50 \%$ de las ventas netas & $0,2 \%$ \\
\hline Más de $50 \%$ de las ventas netas & $0,1 \%$ \\
\hline
\end{tabular}

\section{- Criterio cuallitativo}

El procedimiento para establecer los niveles de error tolerable de cada partida de los estados financieros considera también los niveles evaluados de riesgo de incorrección inmaterial de cada partida, detallado por sus componentes de riesgo inherente y riesgo de control.

La firma de auditores califica los niveles de riesgo inherente y de control de las diferentes partidas en cuatro $\gg$ 
8) categorías, las cuales se califican de 1 a 4 en forma ascendente según el nivel de riesgo, tal y como se detalla a continuación:

\section{" Riesgo inherente}

En el cuadro 2 se detallan las categorías, puntajes y criterios para la valoración del riesgo inherente.

\section{$" \underline{\text { Riesgo de control }}$}

En el cuadro 3 se detallan las categorías, puntajes y criterios para la valoración del riesgo de control.

\section{Cuadro 2: Categorías, criterios y puntajes para la valoración} del riesgo inherente

\begin{tabular}{|c|c|c|}
\hline Categoría & Valor & Explicación \\
\hline Crítico & 4 & $\begin{array}{l}\text { Muy alta probabilidad de incorrección material. } \\
\text { Confluencia de factores como la naturaleza de la cuenta, la complejidad } \\
\text { de cálculos, complejidad de los registros contables y características de } \\
\text { la industria. } \\
\text { Presencia de estimaciones contables complejas sujetas a supuestos e } \\
\text { hipótesis, y al juicio de la gerencia. }\end{array}$ \\
\hline Alto & 3 & $\begin{array}{l}\text { Elevada probabilidad de incorrección material, debido a la confluencia } \\
\text { de los mencionados factores de riesgo inherente. }\end{array}$ \\
\hline Medio & 2 & $\begin{array}{l}\text { Mediana probabilidad de incorrección material. Poca susceptibilidad de } \\
\text { la cuenta a los factores de riesgo inherente. }\end{array}$ \\
\hline Bajo & 1 & $\begin{array}{l}\text { Baja probabilidad de incorrección material, debido a la escasa presencia } \\
\text { de factores de riesgo inherente. }\end{array}$ \\
\hline
\end{tabular}

\section{Cuadiro 3: Categorías, criterios y puntajes para la valoración} del riesgo de control

\begin{tabular}{|c|c|c|}
\hline Categoría & Valor & Explicación \\
\hline Crítico & 4 & $\begin{array}{c}\text { Inexistencia, insuficiencia o ineficacia del sistema de control interno } \\
\text { establecido para detectar o prevenir incorrecciones materiales, por } \\
\text { la presencia de debilidades muy significativas de control que no } \\
\text { neutralizan el riesgo inherente. }\end{array}$ \\
\hline Alto & 3 & $\begin{array}{c}\text { Débil respuesta de control de la entidad, caracterizada por la presencia } \\
\text { de debilidades significativas de control interno. }\end{array}$ \\
\hline Medio & 2 & $\begin{array}{l}\text { Respuesta planeada al riesgo inherente, pero con la presencia de } \\
\text { algunas debilidades importantes en la operación del control interno. }\end{array}$ \\
\hline Bajo & 1 & $\begin{array}{l}\text { Presencia de procedimientos de control interno que mitigan de forma } \\
\text { adecuada los riesgos inherentes de incorrección material. }\end{array}$ \\
\hline
\end{tabular}

\section{" Riesgo de incorrección material}

Una vez valorados el riesgo inherente y el control según se ha explicado, el riesgo de incorrección material se obtiene multiplicando ambos resultados:

\section{Riesgo de incorrección material $=$ Riesgo inherente $\mathrm{x}$ Riesgo de control}

Así, el riesgo de incorrección material adquiere valores entre 1 y 16, dependiendo de las valoraciones específicas del riesgo inherente y del de control. Esto se visualiza en la siguiente matriz, en la que el área sombreada con amarillo representa las combinaciones riesgo inherente-riesgo de control, que resultan en un nivel de riesgo de incorrección material bajo; el área sombreada con verde representa la zona de riesgo de incorrección material moderado; la parte de color naranja es el área de riesgo medio, y dentro del área sombreada con rojo están las combinaciones que constituyen un alto nivel de riesgo de incorrección material(Figura 4).

Teniendo en cuenta lo anterior, los mayores esfuerzos de auditoría deberán ser dirigidos prioritariamente a contrarrestar los altos niveles de riesgo de incorrección material en las partidas cuya combinación riesgo inherente-riesgo de control se ubiquen en la región sombreada con rojo por medio de un enfoque de auditoría concentrado en procedimientos sustantivos. Así sucesivamente en forma descendente, hasta llegar a las partidas cuyas combinaciones resulten en niveles de bajo riesgo de incorrección material, para las cuales podrían aplicarse únicamente pruebas de cumplimiento de los controles y pruebas analíticas. 


\begin{tabular}{|c|c|c|c|c|c|}
\hline \multirow{4}{*}{ 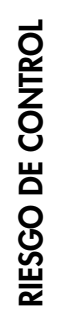 } & 4 & 4 & 8 & 12 & 16 \\
\hline & 3 & 3 & 6 & 9 & 12 \\
\hline & 2 & 2 & 4 & 6 & 8 \\
\hline & 1 & 1 & 2 & 3 & 4 \\
\hline & & 1 & 2 & 3 & 4 \\
\hline & & \multicolumn{4}{|c|}{ RIESGO INHERENTE } \\
\hline
\end{tabular}

\section{Figura 4}

Por ello, para el cálculo de los niveles de error tolerable, la firma de auditores considera que, a mayores niveles evaluados de riesgo de incorrección material, corresponden porcentajes menores de error permisible. Para ello se aplica la siguiente escala:

\begin{tabular}{|c|c|}
\hline $\begin{array}{c}\text { Nivel evaluado de riesgo } \\
\text { de incorrección material }\end{array}$ & $\begin{array}{c}\text { Porcentaje } \\
\text { por aplicar } \\
\text { al saldo de la } \\
\text { partida }\end{array}$ \\
\hline De 13 a 16 & $0,5 \%$ \\
\hline De 9 a 12 & $1,0 \%$ \\
\hline De 5 a 8 & $1,5 \%$ \\
\hline De 1 a 4 & $2,0 \%$ \\
\hline
\end{tabular}

En el cuadro 4 se resumen los resultados de la valoración del riesgo inherente y del riesgo de control de cada cuenta:

Cuadiro 4: Información sobre el riesgo inherente y de control de las partidas de los estados financieros

\section{Partida}

Efectivo y equivalentes

Instrumentos

financieros al valor razonable con cambios en resultados

Cuentas por cobrar a clientes, neto

Ventas

Inventarios y costo de ventas

\section{Elementos de riesgo inherente}

Tres cuentas corrientes.

Registros contables no complejos.

Normal volumen de transacciones.

Inversión en dos títulos de deuda del Gobierno de

Costa Rica, custodiados por entidades externas.

Poco volumen de transacciones.

El valor razonable se determina por un vector de precios y es informado mensualmente por la entidad que custodia los títulos.

La compañía vende principalmente a crédito. Tiene más de 150 clientes en todo el país.

Alto volumen de transacciones.

Estimaciones requeridas para calcular el grado de deterioro e incobrabilidad de la cartera.

Alto riesgo de incobrabilidad de varios clientes.

Lentitud en el cobro de la cartera.

Elevado volumen de transacciones.

La valuación de inventarios de materia prima requiere de cálculos de costos de importación complejos para asignar los costos de importación a los diferentes productos.

\section{Elementos de riesgo de control}

Control interno efectivo, sin debilidades significativas.

Se concilian todos los meses y se confirma con la entidad bancaria el saldo de la cuenta.

Control interno efectivo, sin evidencia de debilidades importantes.

Todos los meses se reciben estados de cuenta y se actualizan los registros contables.

La Auditoría Interna realiza confirmaciones de saldos cada tres meses.

Control interno con muchas deficiencias.

El registro auxiliar no es conciliado todos los meses con el saldo de la cuenta en los estados financieros. Se presentan diferencias importantes entre estos saldos.

Personal de ventas realiza funciones de cobro.

Sistema automatizado de facturación presenta inconsistencias, lo que obliga a realizar reprocesos.

Se ha diseñado y puesto en operación un sistema de control interno adecuado.

Registros auxiliares actualizados.

Una unidad dedicada exclusivamente al control de 
Los inventarios se miden según el costo o el valor neto realizable, el menor. Dificultad para determinar el valor realizable.

Productos sujetos a alto riesgo de obsolescencia $\mathrm{y}$ deterioro.

Se mantiene un sistema de contabilidad de costos de productos múltiples.

Los costos de producción de las diferentes líneas se determinan por medio de un sistema de costo estándar.

Propiedad, planta y equipo, neto

Cuentas por pagar a proveedores

mpuesto sobre la renta por pagar

Gastos acumulados

Documentos por pagar a largo plazo y porción corriente

Capital en acciones

Utilidades acumuladas

Gastos de operación (ventas y administración)

Gastos financieros
Nivel medio de movimientos y transacciones. Se contabilizan al costo menos depreciación acumulada.

Poca complejidad en los procedimientos de contabilización.

La mayoría de los proveedores son del exterior. Cierto grado de incertidumbre por las posibles diferencias entre los montos facturados por los proveedores y los montos declarados en la aduana.

Cierta complejidad en la conciliación entre la utilidad neta financiera y la renta neta.

En los últimos diez años la empresa ha sido auditada por la Dirección General de Tributación en dos ocasiones, dando como resultado ajustes a la renta neta y al impuesto declarado.

Consiste en cuentas de pasivo acumulado por servicios públicos y a la Caja Costarricense de Seguro Social. Movimientos contables poco complejos y predecibles.

La compañía tiene solamente un préstamo bancario con el Banco Nacional de Costa Rica, en colones. Bajo volumen de transacciones, sin complejidades de registro contable.

Saldo sin movimiento desde hace cinco años. Ninguna complejidad de registro contable: solamente se realizó una emisión de acciones cuando se constituyó la empresa.

\section{Ninguna complejidad de registro contable.}

No presenta movimientos extraordinarios ni correcciones de errores de las utilidades.

Poca complejidad en el registro contable de los gastos. Montos fijos y predecibles en la mayoría de las partidas. los inventarios realiza recuentos físicos, verifica la asignación de los costos de las importaciones, da seguimiento a la rotación de inventarios y analiza los registros de los costos de producción y venta.

La Auditoría Interna ejecuta programas de revisión regular de los controles internos de los inventarios.

Diseño y operación de un sistema de control interno adecuado.

Registros auxiliares conciliados todos los meses con los estados financieros.

Listados sobre la ubicación física de los activos. Inventarios físicos cada tres meses.

Diseño y operación del sistema de control interno adecuados, con la presencia de algunas debilidades. El registro auxiliar de proveedores es conciliado, pero en algunos meses esto se hizo con cierto retraso.

Se evidencian debilidades relevantes de control interno. La dirección de la entidad no concilia regularmente la utilidad neta financiera y la renta neta.

No se dispone de controles ni de políticas para identificar y valorar riesgos y contingencias tributarias.

Diseño y operación de un sistema de control interno adecuado. Sin evidencia de debilidades relevantes de control interno.

Diseño y operación de un sistema de control interno adecuado, sin evidencia de debilidades significativas.

Regularmente se realizan confirmaciones con la entidad bancaria.

Sin evidencia de debilidades relevantes de control interno. Registros de accionistas actualizados y conciliados con los estados financieros.

Sin evidencia de debilidades relevantes de control interno.

Diseño y operación de control interno de gastos adecuado. Sin evidencia de debilidades relevantes de control. 


\section{Integración de los criterios-Cálculo del error tolerable por partida}

Una vez realizadas las valoraciones correspondientes a cada partida, según los criterios explicados, la firma procede a integrarlas para determinar el porcentaje y el importe monetario de error tolerable de cada una de las partidas de los estados financieros.

El error tolerable de la partida Utilidad neta del periodo del estado de situación financiera equivale a la sumatoria de los errores tolerables del estado del resultado integral.

\section{RESULTADOS DE LA APLICACIÓN DE LA METODOLOGÍA}

\section{Importes de error tolerable para las partidas de los estados financieros}

Los montos de error tolerable se calculan aplicando dos criterios definidos para ello:

a. El criterio cualitativo, basado en la valoración preliminar del riesgo inherente y del riesgo de control de cada partida.

b. El criterio cuantitativo, basado en el peso relativo de cada cuenta respecto al total de activos, o a las ventas netas, según corresponda.

Posteriormente, se integran ambos criterios y se obtienen los porcentajes y los importes de error tolerable correspondientes a cada partida.

\section{a. Criterio cuallitativo}

En el cuadro 5 se exponen los resultados de la valoración del riesgo inherente y del riesgo de control, realizada siguiendo la metodología que se ha descrito y con base en la información del cuadro 4.

Para la evaluación del riesgo inherente se asignaron puntajes de 1 a 4, según los niveles de riesgo establecidos en el cuadro 4. Lo mismo se hizo al valorar el riesgo de control.

\section{b. Criterio cuantitativo e integración de los resultados}

En los cuadros 7 y 8 se calculan los errores tolerables de las partidas de cada estado financiero siguiendo el criterio cuantitativo y se procede a la integración de los resultados de ambos criterios.

Como se puede observar, la suma de los máximos errores permitidos para cada una de las cuentas $(348,7)$ no supera la

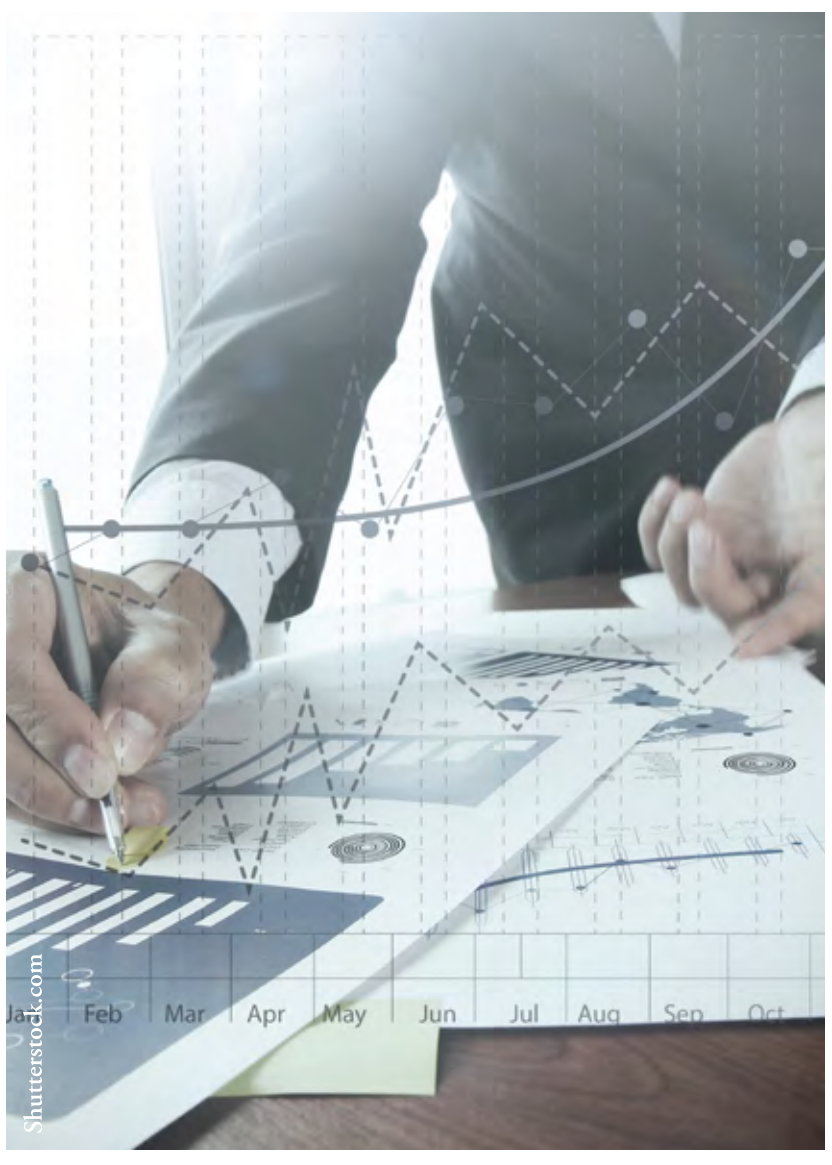

materialidad del estado de situación financiera como un todo, establecida en 351,5 millones, cifra que equivale al 6,5\% del activo total (5.408).

El importe del error tolerable de la utilidad neta del período equivale a la suma de las incorrecciones permitidas en las diferentes partidas componentes del estado de resultados integral.

En el estado de resultado integral también el total de incorrecciones permitidas (24,9 millones) en el nivel de cuentas está por debajo de la materialidad establecida en 27,9 para dicho estado financiero como un todo.

\section{Materialidad de diferentes secciones del estado de situación financiera}

Puede comprobarse en el cuadro 9 que la suma total de errores tolerables en las secciones seleccionadas de este estado no alcanzan los respectivos niveles de materialidad establecidos, lo que contribuye a lograr el objetivo de minimizar el riesgo de auditoría. 
Cuadro 5: Valoración del riesgo inherente y de control, cálculo del riesgo de incorrección material y asignación de porcentaje de error tolerable por cuenta

\section{COMPAÑÍA PRODUCTORA DE ALIMENTOS PARA MASCOTAS S.A.}

AUDITORÍA DE ESTADOS FINANCIEROS AL 30 DE SETIEMBRE DEL 2015

RIESGO DE INCORRECCIÓN MATERIAL POR PARTIDA

\begin{tabular}{|c|c|c|c|c|c|}
\hline \multirow[b]{2}{*}{ ACTIVO } & \multirow[b]{2}{*}{ SALDO } & \multicolumn{3}{|c|}{ VALORACIÓN RIESGO } & \multirow{2}{*}{$\begin{array}{c}\text { \% ERROR } \\
\text { TOLERABLE }\end{array}$} \\
\hline & & INHERENTE $\quad X$ & CONTROL = & TOTAL & \\
\hline Activo Corriente & & & & & ASIGNADO \\
\hline Efectivo y equivalentes & 120 & 1 & 1 & 1 & $2 \%$ \\
\hline $\begin{array}{l}\text { Instrumentos financieros al valor razonable con } \\
\text { cambios en el estado de resultados }\end{array}$ & 206 & 1 & 1 & 1 & $2 \%$ \\
\hline Cuentas por cobrar, importe neto & 694 & 4 & 4 & 16 & $0.5 \%$ \\
\hline Inventarios & 2,128 & 4 & 1 & 4 & $2 \%$ \\
\hline Total activo corriente & 3,148 & & & & \\
\hline \multicolumn{6}{|l|}{ Activo no corriente } \\
\hline Propiedad, planta y equipo, neto & 2,260 & 2 & 1 & 2 & $2 \%$ \\
\hline TOTAL ACTIVO & 5,408 & & & & \\
\hline
\end{tabular}

\section{PASIVO Y PATRIMONIO}

\section{Pasivo Corriente}

Cuentas por pagar a proveedores

Gastos acumulados

Impuesto sobre la renta por pagar

Vencimientos corrientes préstamos a largo plazo

VALORACIÓN RIESGO

TOLERABLE

ASIGNADO

\section{$2 \%$}

$2 \%$

$5 \%$

$2 \%$

Total de pasivo corriente

1,620

\section{Pasivo no corriente}

Préstamos por pagar a largo plazo

1,850

$990 \quad 2$

255

125

250

1

1

3

1
3,470

TOTAL DE PASIVO

\section{PATRIMONIO}

Capital en acciones comunes

Utilidades acumuladas

400

1,073

1

Utilidad neta del periodo

TOTAL DE PATRIMONIO

TOTAL DE PASIVO Y PATRIMONIO
465

1,938

5,408 
Cuadro 6: Valoración del riesgo inherente y de control, cálculo del riesgo de incorrección material y asignación de porcentaje de error tolerable por cuenta

COMPANIÍA PRODUCTORA DE ALIMENTOS PARA MASCOTAS S.A.

AUDITORÍA DE ESTADOS FINANCIEROS AL 30 DE SETIEMBRE DEL 2015

ESTADO DE RESULTADOS INTEGRAL

AÑO TERMINADO EL 30 DE SETIEMBRE DE 2015

\begin{tabular}{|c|c|c|c|c|c|}
\hline & \multirow[b]{2}{*}{ SALDO } & \multicolumn{3}{|c|}{ VALORACIÓN RIESGO } & \multirow{2}{*}{$\begin{array}{l}\% \text { ERROR } \\
\text { TOLERABLE } \\
\text { ASIGNADO }\end{array}$} \\
\hline & & INHERENTE $\quad X$ & CONTROL = & TOTAL & \\
\hline Ventas & 1300 & 4 & 4 & 16 & $0.5 \%$ \\
\hline Costo de ventas & 425 & 4 & 1 & 4 & $2.0 \%$ \\
\hline Utilidad bruta & 875 & & & & \\
\hline Gastos de operación & 130 & 1 & 1 & 1 & $2.0 \%$ \\
\hline Utilidad neta de operación & 745 & & & & \\
\hline Gastos financieros & 155 & 1 & 1 & 1 & $2 \%$ \\
\hline Utilidad antes de impuesto sobre la renta & 590 & & & & \\
\hline Impuesto sobre la renta & 125 & 3 & 3 & 9 & $1.0 \%$ \\
\hline Utilidad neta después de impuestos & 465 & & & & \\
\hline
\end{tabular}

\section{》CONCLUSIÓN}

Siguiendo la propuesta metodológica, se pone de relieve cómo una firma de auditoría o un auditor independiente pueden establecer las bases para disminuir el riesgo de detección y, con esto, reducir a un nivel adecuado el riesgo de auditoría.

La firma estableció importes de materialidad para cada una de las cuentas de los estados financieros de la entidad auditada para las distintas secciones del estado de situación financiera y para cada uno de los estados financieros, con base en dos criterios clave: el peso relativo de cada cuenta en el respectivo estado financiero y los niveles de riesgo inherente y de control evaluados por los auditores para cada una de esas cuentas.

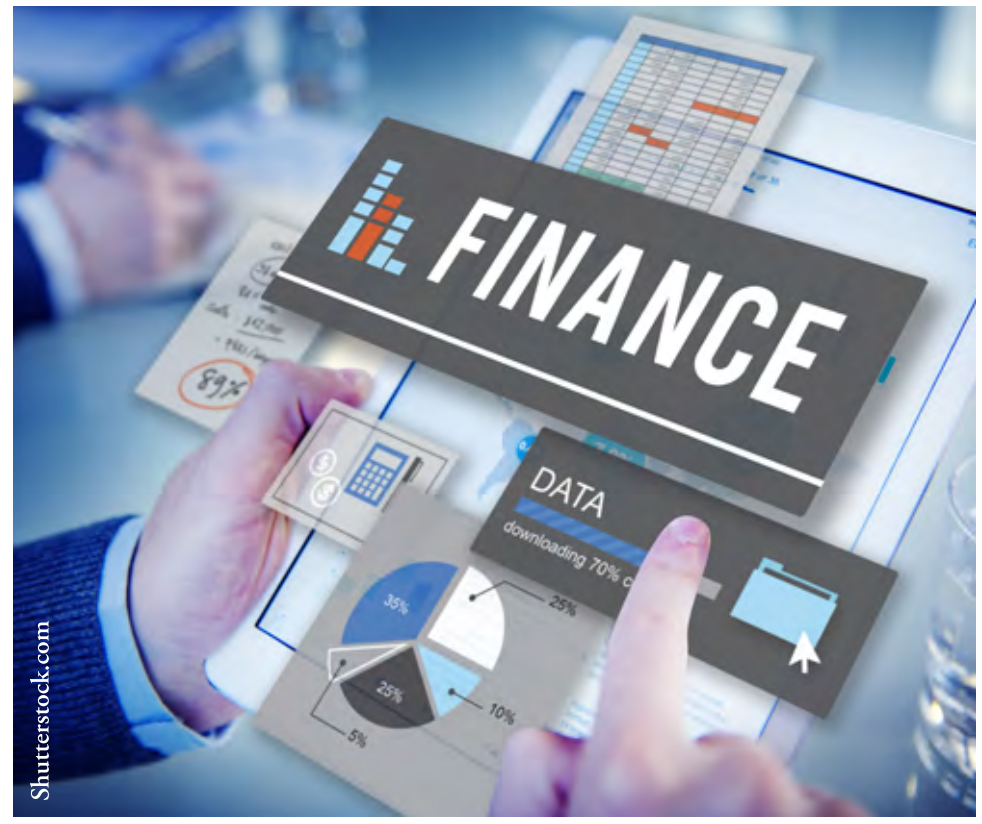


Cuadro 7: Errores tolerables de las partidas del estado de situación financiera

COMPANIÍA PRODUCTORA DE ALIMENTOS PARA MASCOTAS S.A.

AUDITORÍA DE ESTADOS FINANCIEROS AL 30 DE SETIEMBRE DEL 2015

RIESGO DE INCORRECCIÓN MATERIAL POR PARTIDA

\begin{tabular}{|c|c|c|c|c|c|c|}
\hline \multirow[b]{2}{*}{ ACTIVO } & & \multirow[b]{2}{*}{ \% ACTIVO } & \multicolumn{3}{|c|}{ FACTORES ERROR TOLERABLE } & \multirow{2}{*}{$\begin{array}{r}\text { ERROR } \\
\text { TOLERABLE }\end{array}$} \\
\hline & & & IMP & RIESGO & & \\
\hline Activo Corriente & & TOTAL & RELATIVA & INC MAT & TOTAL & MONTO \\
\hline Efectivo y equivalentes & 120 & $2.22 \%$ & $1.50 \%$ & $2.00 \%$ & $3.50 \%$ & 4.2 \\
\hline $\begin{array}{l}\text { Instrumentos financieros al valor razonable con } \\
\text { cambios en el estado de resultados }\end{array}$ & 206 & $3.81 \%$ & $1.50 \%$ & $2.00 \%$ & $3.50 \%$ & 7.2 \\
\hline Cuentas por cobrar, importe neto & 694 & $12.83 \%$ & $1.50 \%$ & $0.50 \%$ & $2.00 \%$ & 13.9 \\
\hline Inventarios & 2,128 & $39.35 \%$ & $1.25 \%$ & $2.00 \%$ & $3.25 \%$ & 69.2 \\
\hline Total activo corriente & 3,148 & $58.21 \%$ & & & & \\
\hline \multicolumn{7}{|l|}{ Activo no corriente } \\
\hline Propiedad, planta y equipo, neto & 2,260 & $41.79 \%$ & \multirow[t]{2}{*}{$0.75 \%$} & \multirow[t]{2}{*}{$2.00 \%$} & \multirow[t]{2}{*}{$2.75 \%$} & \multirow[t]{2}{*}{62.2} \\
\hline TOTAL ACTIVO & 5,408 & $100.00 \%$ & & & & \\
\hline \multirow{2}{*}{\multicolumn{7}{|c|}{$\begin{array}{l}\text { PASIVO Y PATRIMONIO } \\
\text { Pasivo Corriente }\end{array}$}} \\
\hline & & & & & & \\
\hline Cuentas por pagar a proveedores & 990 & $18.31 \%$ & $1.50 \%$ & $2.00 \%$ & $3.50 \%$ & 34.7 \\
\hline Gastos acumulados & 255 & $4.72 \%$ & $1.50 \%$ & $2.00 \%$ & $3.50 \%$ & 8.9 \\
\hline Impuesto sobre la renta por pagar & 125 & $2.31 \%$ & $1.50 \%$ & $1.00 \%$ & $2.50 \%$ & 3.1 \\
\hline Vencimientos corrientes préstamos a largo plazo & 250 & $4.62 \%$ & \multirow[t]{2}{*}{$1.50 \%$} & \multirow[t]{2}{*}{$2.00 \%$} & \multirow[t]{2}{*}{$3.50 \%$} & \multirow[t]{2}{*}{8.8} \\
\hline Total de pasivo corriente & 1,620 & $29.69 \%$ & & & & \\
\hline \multicolumn{7}{|l|}{ Pasivo no corriente } \\
\hline Préstamos por pagar a largo plazo & 1,850 & $34.21 \%$ & \multirow[t]{2}{*}{$1.25 \%$} & \multirow[t]{2}{*}{$2.00 \%$} & \multirow[t]{2}{*}{$3.25 \%$} & \multirow[t]{2}{*}{60.1} \\
\hline TOTAL DE PASIVO & 3,470 & $61.16 \%$ & & & & \\
\hline \multicolumn{7}{|l|}{ PATRIMONIO } \\
\hline Capital en acciones comunes & 400 & $7.40 \%$ & \multirow{5}{*}{$\begin{array}{l}1.50 \% \\
1.50 \%\end{array}$} & \multirow{5}{*}{$\begin{array}{l}2.00 \% \\
2.00 \%\end{array}$} & \multirow{5}{*}{$\begin{array}{l}3.50 \% \\
3.50 \%\end{array}$} & 14.0 \\
\hline Utilidades acumuladas & 1,073 & $19.84 \%$ & & & & 37.6 \\
\hline Utilidad neta del periodo & 465 & $8.60 \%$ & & & & 24.9 \\
\hline TOTAL DE PATRIMONIO & 1,938 & $35.84 \%$ & & & & \\
\hline TOTAL DE PASIVO Y PATRIMONIO & 5,408 & $100.00 \%$ & & & & \\
\hline
\end{tabular}


DEl hecho de que las sumas de los errores permisibles para una partida no alcancen los niveles de materialidad establecidos para cada uno de los estados financieros en su conjunto, permite tener una seguridad razonable de que el total de incorrecciones materiales que llegasen a identificar los auditores, conjuntamente con las posibles incorrecciones materiales que no logren determinar (riesgo de detección), no alcancen la materialidad para cada estado financiero y para el conjunto de los estados financieros. $\gg$

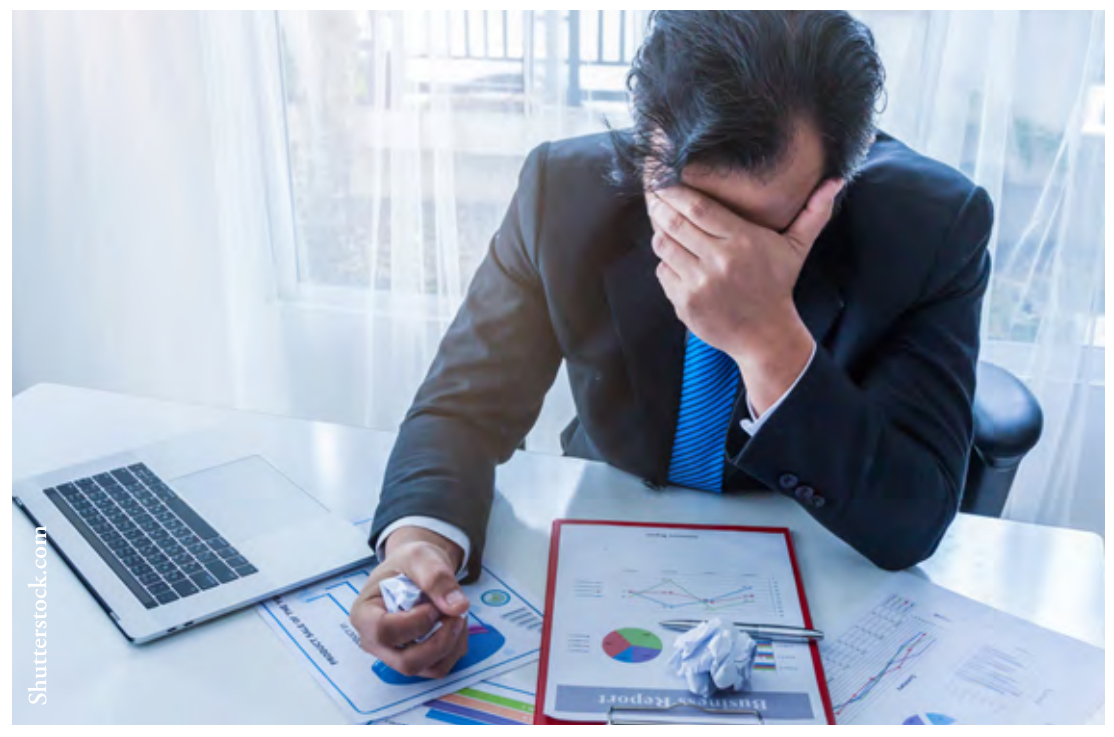

Cuadiro 8: Errores tolerables de las partidas del estado de resultados integral COMPAÑÍA PRODUCTORA DE ALIMENTOS PARA MASCOTAS S.A. AUDITORÍA DE ESTADOS FINANCIEROS AL 30 DE SETIEMBRE DEL 2015 ESTADO DE RESULTADOS INTEGRAL

AÑO TERMINADO EL 30 DE SETIEMBRE DE 2015

(cifras en millones de colones)

Ventas

Costo de ventas

Utilidad bruta

Gastos de operación

Utilidad neta de operación

Gastos financieros

Utilidad antes de impuesto sobre la renta

Impuesto sobre la renta

Utilidad neta después de impuestos

Materialidad para el ERI en conjunto
MONTO

1300

425

875

130

745

155

590

125

465

$6.00 \%$

27.9

\section{FACTORES ERROR TOLERABLE}

IMP

ERROR TOLERABLE RELATIVA INC MAT TOTAL

MONTO NETAS

$0.10 \%$

$0.5 \%$

$0.6 \%$

7.80

$32.69 \%$

$0.20 \%$

$2.0 \%$

$2.2 \%$

9.35

$10.00 \%$

$0.20 \%$

$2.0 \%$

$2.2 \%$

2.86

$11.92 \%$

$0.20 \%$

$2.0 \%$

$2.2 \%$

3.41

$9.62 \%$

$0.20 \%$

$1.0 \%$

$1.2 \%$

1.50 
Cuadro 9: Niveles de materialidad para secciones del estado de situación financiera
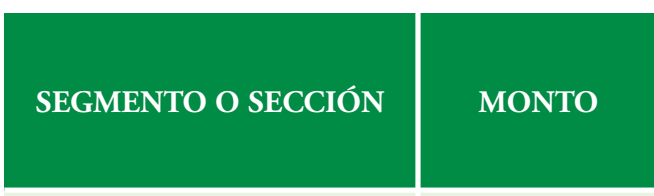

Total de activo corriente

Total de pasivo corriente

Total de pasivos

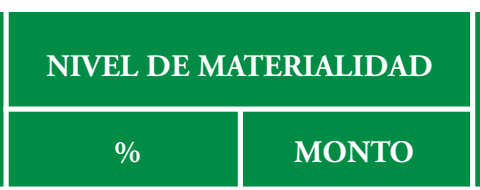

141,7

72,9

$1.620,0$

$3.470,0$

\begin{tabular}{|l|}
\hline $4,5 \%$ \\
\hline $4,5 \%$ \\
\hline $5,0 \%$ \\
\hline
\end{tabular}

\begin{tabular}{|l|}
\hline 141,7 \\
\hline 72,9 \\
\hline 173,5 \\
\hline
\end{tabular}

ERROR
TOLERABLE
ACUMULADO
(Estado de Situación)

94,45

55,45

161,1
\La definición de la materialidad en cualquiera de los niveles es un asunto que encierra juicio profesional del auditor, aunque para efectos prácticos ese juicio se resume en la aplicación de unos porcentajes a los saldos de ciertos referentes de los estados financieros, como se ha ilustrado.

La selección de la metodología, los referentes y los porcentajes para determinar la materialidad son asunto de criterio profesional. Cada auditor puede adoptar los criterios que mejor se ajusten para el logro del objetivo de minimizar el riesgo de auditoría, y la propuesta formulada puede contribuir a ello.

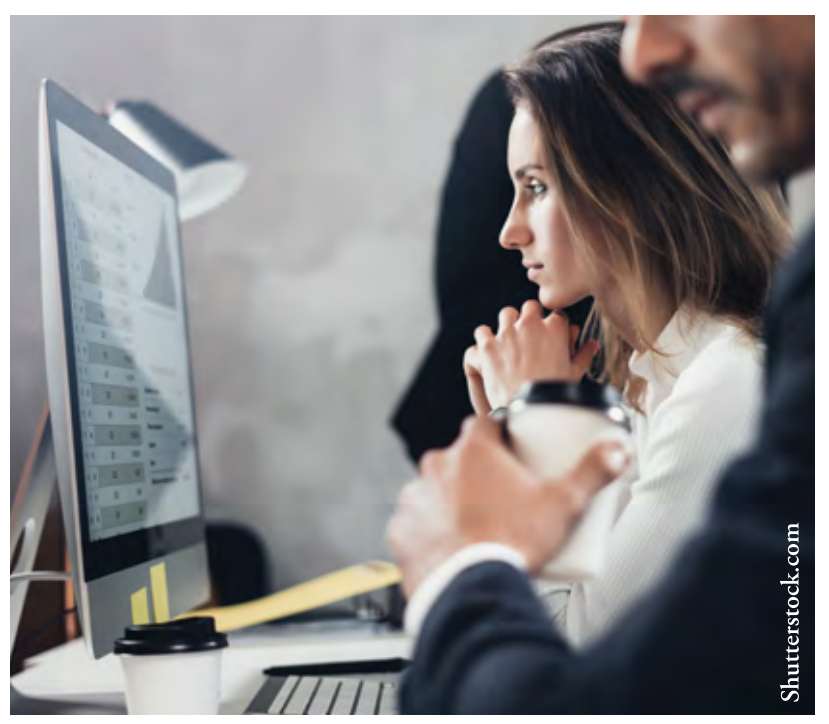

\section{Referencias Bibliográficas:}

Arens, A., Elder, R. y Breasley, M. (2007). Auditoría un enfoque integral. México: Pearson.

Gutiérrez, A. y Maz, A. (s.f.). Cimentando un proyecto de investigación: la revisión de literatura. Disponible en http://www.uv.es/ gutierre/aprengeom/archivos2/homenaje/10GutierrezA.PDF.

International Accounting Standard Board [IASB]. (2011). Normas Internacionales de Información Financiera. Londres: Fundación del Comité de Normas Internacionales de Contabilidad.

International Federation of Accountants [IFAC]. 2011. Normas Internacionales de Auditoría. México, D.F.: Instituto Mexicano de Contadores Públicos, A.C.

Mendoza, J.. (2009). Detección del fraude en una auditoría de estados financieros. Perspectivas. Disponible en http://www.redalyc.org/ articulo.oa? id= 425942160012 .

Mercado, H.J. (2010). Auditoría de estados contables basada en la evaluación de riesgos. Disponible en http://www.eco.unlpam.edu.ar/ objetos/materias/contador-publico/4-ano/control-interno-y-auditoria/aportes-teoricos/Riesgo\%20de\%20Auditoria.pdf.

Quintanar, E. (1985). Modelos de riesgos, factores de confianza y conceptos estadísticos aplicados a la auditoría. Revista Española de Financiación y Contabilidad. (15), 449-455.

Whittington, O. y Pany, K. (2006). Principios de auditoría. México: Mc Graw Hill. 